\title{
UK and space science
}

SIR - The European Space Agency (ESA) faces difficult decisions, as indicated by your recent news report ${ }^{1}$ and the correspondence from Bleeker and Woltjer $^{2}$. They, of course, are the architects of ESA's Horizon 2000 and 2000+ programmes, the troubled centrepieces of ESA's flagship scientific programme.

You have already reported that the United Kingdom has been unable to contribute planned instrumentation hardware to the gamma-ray satellite Integral ${ }^{3,4}$. The reconfiguration of Integral's payload arrangements is not yet assured. Italy has offered to fill the gap left by the United Kingdom. But Italy is, as a consequence, in difficulties over its intended contribution to the UK-led optical Monitor instrument for the XMM mission.

Following advice from ESA, this instrument has been de-scoped and reconfigured (with a proposed small extra contribution from the United Kingdom which, happily, we are able to make). It is generally known in the space community that Germany has been negotiating a reduced contribution both to Integral and, like the United Kingdom, to Rosetta.

ESA's science directorate is responding with imaginative ad hoc arrangements that are producing real savings in the procurement of the instrumental payloads of XMM, Integral and Rosetta; studies are being carried out to determine how savings can be made on the larger costs associated with the spacecraft.

But the structural problem remains: European space scientists are progressively unable to make the 'in kind' contributions to the ESA space science payloads that have been planned. In some cases they have also been unable to afford the ESA space science subscription. The balance of the ESA programme has gone wrong, with national contributions under increasing strain because of the increase in subscriptions in the past decade and the tough economic climate in Europe.

Like Bleeker and Woltjer, we should all be concerned at the effects of this imbalance on our creative young scientists and engineers, who are supported by the national funds associated with the ESA subscription.

Britain is not alone in its difficulty. ESA has already shown its flexibility in responding to requests from Spain and Ireland for special measures to alleviate their space science subscriptions to ESA. Like the United Kingdom, Germany wants to reduce its subscription, and other countries have their own concerns.

At the same time, ESA member states have become increasingly aware that the agency cannot deliver everything they want. France is proposing to set up a small satellite science programme outside the
ESA framework. Germany and Italy, like the United Kingdom, are looking at national and bilateral space missions as an inexpensive complement to ESA's big missions. The Scandinavian countries are investing in their own national space programmes.

ESA states are also aware that the US National Aeronautics and Space Administration (NASA), which has gone through a very difficult time, is putting reforms in place with a 'smaller, cheaper, faster' policy for missions that is intended to make the agency more effective.

The ESA Council is recently reported to have commissioned consultants to study how the agency can make itself more efficient, particularly in its handling of industrial contracts and in its management practices 5 . No figure has yet been revealed to indicate how much the proposed reforms might reduce ESA's costs. But the conclusions and recommendations of the study are far-reaching.

Professor Mike Cruise estimates that, even if ESA continues with its present industrial policy, the science programme can save 10-15 per cent on the STEP satellite mission, which he is proposing to ESA. On the basis of earlier studies and comparisons with national missions and using the most recent studies for confirmation - the United Kingdom has set a target of 25 per cent for the savings that, altogether, it believes are possible, and which Bleeker and Woltjer assert are not.

They point with justifiable pride to the achievements of the ESA science programme. British scientists are equally proud to have played their part in this success story. To ensure their continued part in this success, and aware that we need our European colleagues equipped to work with us, the United Kingdom has put forward proposals for savings and changes in procedures in the ESA science programme. We believe our proposals will restore the balance between the national and international components of European space science, producing a leaner and more responsive space science programme with the same scientific output.

The future of ESA depends on accepting the challenge of competition in the real world. Is it really true, as Bleeker and Woltjer suggest, that these perturbations will have a "devastating effect" on ESA's space science programme? If so, the future is certainly bleak, as these perturbations are surely here already.

We need not just a blanket denial of the situation, but a positive response to the challenge of the conditions of the millennium years to ensure that European space science fulfils the future promised by Horizon 2000 and $2000+$. Such a response is coming, not only from the space scien- tists of Europe - including the United Kingdom - confident in the future of both ESA and space science, and working together to create that future, but also from those in the ESA family prepared to change the severe external constraints under which the ESA science programme has to operate.

Paul Murdin

(Head of Astronomy)

Particle Physics

and Astronomy Research Council, Polaris House, North Star Avenue,

Swindon SN2 1SZ, UK

SIR - In "Britain gets a rough ride over call for space cuts"1, I was extensively quoted. The article accurately reflects my views, but not the location of the institute at which I work. Given the political heat being generated over the issue, I am not sure to which institute you should apologize but, to set the account straight, I am based at the Rutherford Appleton Laboratory, not at the University of Sheffield.

\section{A. M. Cruise}

Rutherford Appleton Laboratory,

Chilton, Didcot,

Oxfordshire OX11 OQX, UK

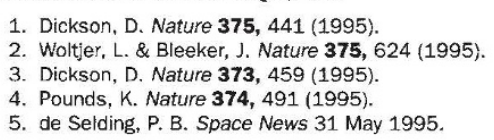

\section{Worthy journals}

SIR — You defend (Nature 375, 11; 1995) the proliferation of scientific journals on the grounds that on browsing through some randomly selected issues, you found articles of interest in all of them.

I cannot assess the status of the journals in the physical sciences at which you looked. But it is striking that the two biomedical journals included The Lancet and The New England Journal of Medicine, which are, unquestionably, top-ranking serials in the field. It would be surprising, therefore, if every issue did not contain something worth noting.

But this is not in itself the issue of concern about the continuing emergence of new titles. There is a finite limit to the number of specialist journals that can coexist before standards of reviewing and data reliability become noticeably reduced. One could argue that this is itself damaging to the long-term integrity of the scientific process. On a more pragmatic level, the more competition for limited subscription funds between journals, the less efficient the publication process becomes. Surely this at least partly underlies the startling rate at which subscription prices are outstripping the capacity of libraries to sustain their holdings.

\section{Christopher Bell}

Department of Physiology,

Trinity College, Dublin 2, Ireland 